\title{
PENERJEMAHAN RENCANA STRATEGI MENJADI PROGRAM KEGIATAN MENGGUNAKAN BALANCED SCORECARD UNTUK PENGUKURAN KINERJA DAN AKUNTABILITAS DINAS LALU LINTAS DAN ANGKUTAN JALAN
}

\author{
Wahyudi $^{\mathrm{a}}$ \\ Bambang Tjahjadi ${ }^{\mathbf{b}}$ \\ ${ }^{a}$ Sekolah Pascasarjana Universitas Airlangga ${ }^{b}$ Fakultas Ekonomi dan Bisnis Universitas Airlangga \\ Email: wahyudi004@tutanota.com ${ }^{\mathrm{a}}$; bambang.tjahjadi@feb.unair.ac.id ${ }^{\mathrm{b}}$
}

ARTICLE HISTORY

Received:

12 July 2020

Revised

11 September 2020

Accepted:

14 Oktober 2020

Online available:

24 November 2020

Keywords:

Strategic Plan,

Target,

Initiative,

Budget,

Balanced Scorecard

\section{ABSTRACT}

Introduction: The purpose of this study is intend to knowing the level of understanding of person who make initiative related to the strategic plan of Dinas Lalu Lintas dan Angkutan Jalan Provinsi Jawa Timur; also knowing the methods used in elaborating a strategic plan into initiative; c. Knowing the performance measurement has been using as expected; and provide input regarding the efforts that need to be done in translating strategic plans.

Methods: This study uses the Balanced Scorecard model as a strategic management system to translate the strategic plan into an activity program at the Road Traffic and Transportation Office of East Java Province.

Results: The results of this research indicated that a Vision Statement Dinas Lalu Lintas dan Angkutan Jalan Provinsi Jawa Timur can not provide a clear picture about the success rate to be achieved; b. Mission Statement Dinas Lalu Lintas dan Angkutan Jalan Provinsi Jawa Timur have not been able to demonstrate the importance of the existence of the Office; c. Formulation of document strategic plan Dinas Lalu Lintas dan Angkutan Jalan Provinsi Jawa Timur has not been in accordance with what is expected; d. Realization of the budget that are not effective and not performance oriented; e. Target performance of Dinas Lalu Lintas dan Angkutan Jalan Provinsi Jawa Timur has not been measured or is shaped qualitative rather than quantitative; f. Unavailability of data used as the basis for determining the level of achievement of a initiative.

Conclusion and suggestion: The vision and mission statement of Dinas Lalu Lintas dan Angkutan Jalan Provinsi Jawa Timur needs to be restructure and rearrangement objectives, Goals and Strategies Department.

Jurnal Ekonomi dan Bisnis Airlangga p-ISSN: 2338-2686; e-ISSN: 2597-4564 


\section{INTRODUCTION}

Perkembangan sektor publik di Indonesia diawali dengan menguatnya tuntutan akuntabilitas atas lembaga-lembaga publik, baik di pusat maupun daerah agar lebih efisien dan efektif dalam penggunaan sumber daya. Terbitnya Undang Undang Nomor 25 Tahun 2004 tentang Sistem Perencanaan Pembangunan Nasional mewajibkan setiap instansi pemerintah sebagai unsur penyelenggara pemerintahan negara untuk mempertanggungjawabkan pelaksanaan tugas pokok dan fungsinya serta kewenangan pengelolaan sumber daya dengan didasarkan suatu perencanaan.

Dinas Lalu Lintas dan Angkutan Jalan Provinsi Jawa Timur dalam melaksanakan tugas dan fungsinya di dukung oleh Anggaran Pendapatan dan Belanja Daerah yang disusun setiap tahun sesuai kebutuhan, yang sebelum era reformasi penyusunan anggaran belanja pemerintah dikelompokkan atas anggaran belanja rutin dan anggaran belanja pembangunan yang dalam pelaksanaannya telah menimbulkan peluang terjadinya duplikasi, penumpukan, dan penyimpangan anggaran. Pendekatan yang digunaka dalam menyusun anggaran menggunakan : line item budget yang mengelompokkan pengeluaran berdasarkan jenis dan jumlah totalnya; selain itu penyusunan anggaran menggunakan sistem incremental yang metodenya didasarkan pada anggaran periode sebelumnya sebagai dasar ditambahkan untuk periode anggaran baru yang cenderung menimbulkan mentalitas untuk menghabiskan anggaran bila terdapat sisa anggaran, sehingga menimbulkan pemborosan.

Dinas Lalu Lintas dan Angkutan Jalan Provinsi Jawa Timur sebagai unsur penyelenggara pemerintahan dilingkungan Pemerintah Daerah Provinsi Jawa Timur telah memiliki dokumen rencana strategi yang memuat Visi, Misi, Tujuan, Sasaran, Strategi, Kebijakan dan Program, agar tujuan organisasi dapat terlaksana dan berhasil dengan baik. Rencana strategi yang merupakan suatu upaya mencari tahu dimana organisasi berada saat ini, menentukan arah kemana organisasi harus menuju, dan bagaimana cara (strategi) untuk mencapai tujuan organisasi.

Dinas Lalu Lintas dan Angkutan Jalan Provinsi Jawa Timur dengan visi "Terwujudnya Manajemen dan Rekayasa Lalu Lintas dan Angkutan Jalan pada 
Jalur Utama di Jawa Timur Tahun 2010", maka seluruh personil di lingkup Dinas harus tahu dan memahami visi tersebut karena setiap kebijakan yang akan diambil oleh Dinas harus berpedomana pada visi tersebut, sehingga setiap Sub Dinas dan Bagian Tata Usaha akan memiliki arah tujuan yang jelas dan menjadi kekuatan yang saling mendukung dalam rangka mewujudkan visi Dinas.

Rencana strategi Dinas yang memuat program, kebijakan dan sasaran perlu diterjemahkan menjadi program/kegiatan tahunan yang disertai besaran anggaran yang diperlukan dan target yang hendak dicapai merupakan sesuatu hal yang sangat diperlukan, karena apabila hal tersebut tidak dapat dilaksanakan maka" penyusunan rencana strategis bagi instansi pemerintah yang asalan saja, dan tidak memuat fase implementasi dan evaluasinya dengan benar. Sebagian besar (semua ?) hanya berisi visi dan misi, sehingga tentunya tidak mempunyai arti yang substantif dalam hal akuntabilitas" seperti yang dikemukakan oleh Darmansjah (2003: 5).

Dinas Lalu Lintas dan Angkutan Jalan Provinsi Jawa Timur sebagai salah satu instansi yang bernaung dibawah Pemerintah Daerah Provinsi Jawa Timur, telah menyusun Rencana Strategis untuk 5 tahun yaitu tahun 2006 - 2010. Akuntabilitas sebagai bentuk kewajiban dalam mempertanggungjawabkan melaksanakan visi dan misi organisasi pemerintah dalam hal ini organisasi Dinas Lalu Lintas dan Angkutan Jalan Propinsi Jawa Timur guna mengoptimalkan kinerja, mencapai tujuan dan sasaran yang telah ditetapkan dengan alokasi anggaran yang tersedia.

\section{LITERATURE REVIEW}

\section{The traditional society}

Pemerintah dalam menjalankan tugasnya harus dapat menjelaskan dan mempertanggung jawabkan setiap hasil yang telah dicapai kepada rakyat hal ini sebagaimana yang dikemukakan oleh Bovens (2006: 7) yang mendefinisikan akuntabilitas adalah "the relationship between an actor and a forum, in whichthe actor has an obligation to explain and justify his or her conduct, the forum can pose questions and pass judgment, and the actor may face consequences", dalam menjalankan tugas dan fungsinya pemerintah harus dapat memenuhi harapan dan keinginan masyarakat sebagai pertanggungjawaban terhadap pemanfaatan sumber daya yang digunakan.

Untuk memperoleh gambaran seberapa besar tingkat keberhasilan suatu program/kegiatan perlu dilakukan pengukuran yang menurut Kane dan 
Johnson seperti yang dikutip Suprasto (2006: 4) pengukuran kinerja adalah "gambaran mengenai tingkat pencapaian pelaksanaan suatu kegiatan/program kebijakan organisasi dalam mewujudkan tujuan organisasi, outcome hasil kerja organisasi dalam mewujudkan tujuan strategis yang ditetapkan organisasi, kepuasan pelanggan, serta kontribusinya terhadap perkembangan ekonomi masyarakat". Jadi pengukuran kinerja harus dilakukan oleh instansi pemerintah untuk mengetahui seberapa besar tingkat pencapaian suatu kegiatan/program kebijakan dalam rangka mencapai tujuan strategi organisasi yang telah ditetapkan sebelumnya.

Pengukuran kinerja menurut Behn, et al (1993: 7) memiliki kegunaan yang berbeda, hal ini tercermin dalam pendapatnya bahwa "Performance measures have different uses, according to the defined objectives. They can be used at the operational level, as a control tool; at the strategic level, as a management tool; and in the analysis of the individualperformance." Pengukuran kinerja pada organisasi pemerintah menurut pendapat ini didasarkan pada kebutuhan dibentuknya organisasi tersebut untuk menjalankan fungsi dan tugasnya, dan pengukuran kinerja dibedakan sesuai definisi dan tujuan dilakukannya pengukuran kinerja.

Kaplan dan Norton (1996: 134) mengklaim, bahwa BSC memberikan manajer instrumen yang diperlukan untuk memberikan pedoman kemasa depan guna keberhasilan dalam persaingan. Menterjemahkan misi dan strategis organisasi ke dalam seperangkat pengukuran kinerja yang komprehensif yang memberikan kerangka kerja bagi sistem pengukuran strategis dan manajemen.

Balanced Scorecard sebagai suatu kerangka kerja yang terintegrasi untuk menjabarkan dan menterjemahkan strategi dapat digunakan untuk meningkatkan akuntabilitas dan kinerja menurut Niven (2008: 56) karena Balanced Scorecard menurut Niven bermanfaat untuk "a. Improve Performance; b. Demonstrate Accountability; $c$. Meet Customer and Constituents Needs; d. Align Department and Employee Goals with Organizational Goals; e. Improve Communication within the Department and the Organization"

Sorkin, Ferris, dan Hudak dalam jurnal Kaufman dan Jacob sebagaimana yang dikutip oleh Djunaedi (2000: 5) mengidentifikasi langkah-langkah dasar perencanaan strategi meliputi : 
(1) mengkaji lingkungan (scan the environment); (2) memilih isu-isu kunci (select key issues); (3) merumuskan pernyataan misi atau tujuan umum/visi (set mission statements or broad goals); (4) melakukan kajian eksternal dan internal (undertake external dan internal analyses); (5) mengembangkan tujuan, sasaran, dan strategi yang terkait dengan tiap isu kunci (develop goals, objectives, and strategies with respect to each issue); (6) mengembangkan rencana implementasi untuk menjalankan tindakan-tindakan strategis (develop an implementation plan to carry out strategic actions); (7) memantau, memperbarui, dan mengkaji (monitor, update, dan scan)

Agar rencana strategis dapat berjalan secara baik dan terus berlanjut menurut Willett (2003: 4) diperlukan suatu upaya yang meliputi "(a linking strategy to the budgeting process; ( $b$ regular meetings to review strategy; and (c a process for a learning and adapting' strategy, such as designing a feedback system that reports on organisational progress and can assess the strategy's outcomes." Penentuan sasaran dan target kinerja pada dokumen rencana strategis organisasi harus sesuai dengan alokasi anggaran yang disediakan bagi program/kegiatan yang telah ditentukan. Esensinya adalah bagaimana, mulai dari merencanakan, melaksanakan kemudian mengendalikan dengan harapan agar tujuan organisasi dapat dicapai sesuai dengan fungsinya dalam memberikan pelayanan kepada masyarakat.

Rencaa strategis sebagai dokumen perencanaan Satuan Kerja Perangkat Daerah untuk jangka waktu 5 (lima) tahun harus dimiliki oleh setiap instansi pemerintah di daerah sebagai pedoman dalam melaksanakan program dalam rangka mewujudkan visi dan misi organisasi. Dalam menjalakan tugas dan fungsinya organisasi pemerintah harus dapat menyesuaikan dengan lingkungan dimana organisasi tersebut berada hal ini sebagaimana yang dikemukakan oleh Niven (2008: 133) bahwa strategi adalah "broad priorities adopted by an organization in recognition of its operating environment and in pursuit of its mission"

\section{RESEARCH METHODS}

Pendekatan penelitian yang digunakan adalah bentuk penelitian kualitatif yang didasarkan atas pertanyaan pada pokok masalah yaitu bagaimana menerjemahkan rencana strategis Dinas Lalu Lintas dan Angkutan Jalan Propinsi 
Jawa Timur menjadi program/kegiatan tahunan dalam rangka mewujudkan kinerja dan akuntabilitas. Pembahasan masalah dalam tulisan ini diarahkan pada penggunaan model Balanced Scorecard sebagai sistem manajemen strategis untuk menterjemahkan rencana strategis menjadi program/kegiatan pada Dinas Lalu Lintas dan Angkutan Jalan Propinsi Jawa Timur.

Tabel 1

Alur Pikir Keterkaitan Data dengan Proposisi

\begin{tabular}{|c|c|c|}
\hline PROPOSISI & PENGUMPULAN DATA & DATA \\
\hline $\begin{array}{l}\text { Melalui } \\
\text { penerjemahan } \\
\text { rencana strategis } \\
\text { Dinas LLAJ } \\
\text { Propinsi Jawa Timur } \\
\text { menggunakan } \\
\text { Balanced Scorecard } \\
\text { menjadi program/ } \\
\text { kegiatan tahunan, } \\
\text { dapat menentukan } \\
\text { ukuran kinerja dan } \\
\text { akuntabilitas instansi } \\
\text { pemerintah. }\end{array}$ & $\begin{array}{l}\text { Dokumenter, Wawancara,dan } \\
\text { Obeservasi } \\
\text { - Tugas dan Fungsi Dinas LLAJ Propinsi Jawa } \\
\text { Timur. } \\
\text { - Dokumen rencana strategis dinas. } \\
\text { - Hasil wawancara } \\
\text { - Dokumen pelaksaan anggaran dinas. }\end{array}$ & $\begin{array}{l}\text { - Konsep yang digunakan } \\
\text { untuk menterjemahkan } \\
\text { rencana strategis } \\
\text { menjadi program/ } \\
\text { kegiatan tahunan. } \\
\text { - } \text { Konsep yang digunakan } \\
\text { dalam menyusun } \\
\text { anggaran tahunan. } \\
\text { - Indikator untuk } \\
\text { digunakan kinerja } \\
\text { mengukur } \\
\text { organisasi. } \\
\text { Penentuan program/ } \\
\text { kegiatan strategis } \\
\text { dinas. }\end{array}$ \\
\hline
\end{tabular}

\section{RESULT AND ANALYSIS}

Strategi sebagai langkah tindakan yang akan dilakukan organisasi dalam rangka mewujudkan tujuan dinyatakan dalam visi dan misi. Sementara misi dan visi terkait dengan pernyataan dalam bidang mengapa dan siapa, sedang strategi fokus kepada bagaimana. Sebuah strategi dapat dipahami dengan baik dan dapat dilaksanakan yang dapat menentukan prioritas dimana organisasi akan mengalokasikan sumber daya dan para pegawainya, melalui pernyataan visi dan misinya Dinas Lalu Lintas dan Angkutan Jalan Provinsi Jawa Timur menentukan strateginya sebagai berikut :

Tabel 2.

Strategi Dinas LLAJ Provinsi Jawa timur

\begin{tabular}{cc} 
No. & URAIAN \\
\hline 1. & Memanfaatkan dan melaksanakan program secara terpadu, efektif dan efisien.
\end{tabular}

Published by University of Airlangga.

This is an open access article under the CC BY license (https://creativecommons.org/licenses/by-sa/4.0/) 
Mensosialisasikan solusi pemecahan masalah-masalah tentang manajemen dan

2. rekayasa lalu lintas dan angkutan jalan, meningkatkan pembinaan dan pengawasan lalu lintas dan angkutan jalan.

3. Melaksanakan sistem informasi manajemen lalu lintas dan angkutan jalan

4. Meminimalkan dampak negatif yang timbul dalam penyelenggaraan manajemen dan rekayasa lalu lintas dan angkutan jalan

Sumber : Rencana Strategi Dinas LLAJ Provinsi Jawa Timur

Strategi organisasi disusun berdasarkan visi, misi dan nilai-nilai sebagai acuan organisasi untuk berkembang merespon perubahan di masa datang. analisis yang mengkaitkan antara visi, misi, serta perkembangan lingkungan eksternal berupa peluang dan ancaman serta kekuatan dan kelemahan lingkugan internal organisasi yang dapat digunakan untuk menentukan cita-cita yang ingin diwujudkan, yang menurut Kaplan dan Norton $(2001 ; 75)$ yang baik harus harus memenuhi unsur : strategi sebagai kelanjutan dari pernyataan misi; strategi merupakan suatu hipotesa; strategi mengandung tema; strategi menyelaraskan kegiatan internal untuk mewujudkan tujuan organisasi secara optimal.

Strategi sebagai kelanjutan dari pernyataan misi, untuk itu dalam menyusun strategi harus dapat menterjemahkan misi sehingga setiap kebijakan/ tindakan individu dalam organisasi akan selaras dan mendukung misi, sesuai pembahasan pada pernyataan misi Dinas diperoleh gambaran bahwa misi Dinas belum efektif, berikut ini perbandingan pernyataan misi dan strategi Dinas :

Tabel 3.

Perbandingan Pernyataan Misi dan Strategi Dinas LLAJ Provinsi Jawa timur

\begin{tabular}{|c|c|}
\hline MISI & STRATEGI \\
\hline $\begin{array}{l}\text { a. Mewujudkan keterpaduan manajemen dan } \\
\text { rekayasa angkutan jalan; } \\
\text { b. Meningkatkan pelayanan kelaikan sarana } \\
\text { angkutan jalan; } \\
\text { c. Meningkatkan pengawasan dan pengendalian } \\
\text { lalu lintas dan angkutan jalan; } \\
\text { d. Meningkatkan kualitas dan profesionalisme } \\
\text { aparatur lalu lintas dan angkutan jalan; } \\
\text { e. Mewujudkan sistem informasi manajemen lalu } \\
\text { linas dan angkutan jalan. }\end{array}$ & $\begin{array}{l}\text { a. Memanfaatkan dan melaksanakan program } \\
\text { secara terpadu, efektif dan efisien. } \\
\text { b. Mensosialisasikan solusi pemecahan masalah- } \\
\text { masalah tentang manajemen dan rekayasa lalu } \\
\text { lintas dan angkutan jalan, meningkatkan } \\
\text { pembinaan dan pengawasan lalu lintas dan } \\
\text { angkutan jalan. } \\
\text { c. Melaksanakan sistem informasi manajemen lalu } \\
\text { lintas dan angkutan jalan. } \\
\text { d. Meminimalkan dampak negatif yang timbul } \\
\text { dalam penyelenggaraan manajemen dan } \\
\text { rekayasa lalu lintas dan angkutan jalan }\end{array}$ \\
\hline
\end{tabular}

Sumber : Rencana Strategis Dinas LLAJ Provinsi Jawa Timur

Dari perbandingan diatas memperlihatkan bahwa antara misi dan strategi Dinas tidak singkron antara yang satu dengan yang lainnya, sehingga hubungan antara misi dan visi yang merupakan pernyataan mengenai mengapa 
dan siapa, dengan uraian strategi yang fokus kepada cara untuk mewujdukan citata-cita Dinas tidak terlihat secara jelas.

Strategi sebagai suatu hipotesis; strategi merupakan dasar bagi organisasi untuk menentukan tindakan apa yang akan dilakukan dimasa depan dan menentukan perubahan organisasi dari posisi sekarang ke posisi yang diinginkan, untuk itu dalam uraian strategi Dinas harus secara jelas memperlihatkan program/kegiatan yang akan dilaksanakan dan hasil yang ingin dicapai disertai dengan tolok ukur yang digunakan untuk memberikan gambaran seberapa besar tingkat perubahan yang dicapai dari pelaksanaan program/kegiatan tersebut, namun pada uraian strategi Dinas hal ini tidak ada.

Strategi mengandung tema, tema strategi memungkinkan organisasi untuk fokus menentukan prioritas dalam jangka panjang dan jangka pendek, secara umum tema strategis mencerminkan apa yang harus dilakukan oleh manajemen untuk menentukan keberhasilan organisasi. Tema strategi berkaitan dengan pandangan apa yang harus dilakukan oleh seorang eksekutif secara internal untuk mencapai hasil yang optimal.

Terkait dengan tema strategi yang digunakan oleh Dinas dapat dikatakan bahwa uraian strategi Dinas tidak memiliki tema, yang dampaknya adalah para Kepala Sub Dinas atau Kepala Bagian Tata usaha tidak memiliki pandangan yang dapat digunakan dalam mengambil suatu keputusan atau kebijakan.

Strategi menyelaraskan kegiatan internal untuk mewujudkan tujuan organisasi secara optimal; strategi tidak hanya harus menentukan hasil yang dicapai, tapi juga harus menjelaskan bagaimana cara untuk mencapainya, untuk mengembangkan strategi yang sukses dan berkelanjutan adalah memastikan keselarasan antara kegiatan internal organisasi dan memberikan nilai tambah bagi masyarakat yang dilayani, Dinas Lalu Lintas dan Angkutan Jalan Provinsi Jawa Timur merupakan organisasi pemerintah yang terdiri dari Bagian Tata Usaha, Sub Dinas Penyusunan Program, Sub Dinas Angkutan, Sub Dinas Teknik Sarana dan Prasarana, Sub Dinas Pengendalian Operasional dan Unit Pelaksana Teknis Dinas yang dipimpin oleh seorang Kepala Dinas seharusnya dalam setiap keputusan atau kebijakan berpedoman kepada strategi Dinas agar pelaksanaannya selaras antara Sub Dinas, Bagian Tata Usaha dan Unit Pelaksana Teknis Daerah, namun pada kenyataannya uraian strategi Dinas masih bersifat umum belum memperlihatkan secara jelas cita-cita yang ingin diwujudkan. 
Pengukuran kinerja pada suatu organisasi harus ditetapkan secara jelas dapat terukur. Tujuan dan sasaran didefinisikan melalui sudut pandang masyarakat yang akan dilayani hal ini digunakan untuk mengindentifikasi pengukuran kinerja sistem transportasi, pengukuran kinerja sebagai perwujudan akuntabilitas dan transparansi publik dimaksudkan untuk memberi gambaran kepada para wakil rakyat terhadap peran transportasi dalam kehidupan sosial, sehingga untuk menentukan ukuran kinerja merupakan sesuatu hal yang penting. Penyusunan ukuran kinerja disusun melalui persepektif pelanggan, persepektif keuangan, persepektif proses internal dan persepektif pertumbuhan dan pembelajaran, berfungsi sebagai penerjemahan langsung dari sasaran dari peta strategi yang tujuannya untuk memberikan gambaran kepada organisasi apakah telah mewudukan tujuannya.

Penyusunan program/kegiatan Dinas Lalu Lintas dan Angkutan Jalan Provinsi Jawa Timur disusun masih belum menggunakan metode tertentu sehingga dalam penyusunannya masih mengikuti pola yang lama yaitu hanya berisi mengenai uraian dari Program/Kegiatan sedang tartget kinerja yang ingin dicapai tidak dicantumkan, meskipun pada lampiran menyebutkan tartget kinerja namun hal tersebut bukan merupakan sesuatu yang terukur (angka), tetapi hanya berupa kata-kata seperti "terwujudnya", "terciptanya" dan "tercapainya". Disatu sisi karena keterbatasan sumber daya yang dimiliki Dinas harus mampu menentukan skala prioritas terhadap setiap kegiatan yang akan dilaksanakan sesuai sasaran yang ingin dicapai oleh Dinas.

Target kinerja disusun sebagai alat komunikasi yang dapat menginformasikan organisasi untuk mencapai tingkatan yang diharapkan melalui pengukuran kinerja, yang tujuannya untuk mengarahkan organisasi untuk fokus pada perbaikan terus-menerus dan berusaha untuk lebih baik kinerjanya. Target juga merupakan mekanisme bagi organisasi untuk mengukur efektifitas pengelolaan anggaran dan mendorong akuntabilitas.

Balanced Scorecard tidak hanya fokus pada salah satu unsur keberhasilan organisasi, namun memberikan gambaran secara lengkap mengenai apa yang diperlukan untuk berhasil. Strategi harus memperlihatkan dampaknya bagi pelanggan, persepektif keuangan diperlukan untuk mengukur bagaimana organisasi memanfaatkan dana yang ada secara efisien dalam rangka memberi pelayanan, bagaimana pola kerja didalam organisasi agar hasil kerja yang dicapai dapat optimal dan bagaimana mengembangkan sumber daya manusia dalam rangka mendukung strategi, dan. Setiap elemen memiliki hubungan yang penting dan memiliki hubungan sebab dan akibat. 


\section{CONCLUSION}

Dari hasil penelitian terhadap dokumen Rencana Strategi dan wawancara dengan para pejabat di lingkungan Dinas Lalu Lintas dan Agkutan Jalan diperoleh kesimpulan sebagai berikut:

1. Pernyataan visi harus dapat memberikan gambaran secara jelas mengenai sesuatu yang ingin dicapai sebagai dasar dalam merumuskan strategi dan tujuan, namun sesuai yang tercantum dalam dokumen Rencana Strategi Dinas Lalu Lintas dan Angkutan Jalan Provinsi Jawa Timur, Visi Dinas masih belum/tidak dapat memberikan gambaran secara jelas mengenai tingkat keberhasilan yang ingin dicapai;

2. Pernyataan Misi Dinas Lalu Lintas dan Angkutan Jalan Provinsi Jawa Timur belum dapat memperlihatkan pentingya keberadaan Dinas sehingga dapat memberikan motivasi bagi karyawan dalam bekerja bagi organisasi;

3. Pemahaman pihak pengambil kebijakan di lingkungan Dinas Lalu Lintas dan Angkutan Jalan Provinsi Jawa Timur terhadap konsep rencana strategi yang tidak komprehensif berdampak pada penyusunannya belum sesuai dengan apa yang diharapkan;

4. Minimnya pedoman yang dapat digunakan sebagai acuan untuk menyusun rencana strategi dan cara untuk menjabarkannya menjadi program/kegiatan tahunan, mengakibatkan realisasi anggaran yang tidak efektif dan tidak berorientasi pada kinerja;

5. Target kinerja yang digunakan oleh Dinas Lalu Lintas dan Angkutan Jalan Provinsi Jawa Timur untuk mengukur tingkat keberhasilan program/kegiatan masih belum terukur atau masih berbentuk kualitatif bukan kuantitatif;

Kendala Dinas Lalu Lintas dan Angkutan Jalan Provinsi Jawa Timur untuk dapat menerapkan anggaran berbasis kinerja adalah tidak tersedianya data yang digunakan sebagai dasar dalam menentukan tingkat capaian suatu program/kegiatan.

\section{REFERENCES}

Behn, R. 2003. Why measure performance? Different Purposes require different measures. Public Administration Review (Vol. 63), 1 - 15

Bovens M, Schillemans T. and Hart P. 2006. Does Public Account Ability Work ? an Assessment Tool, Working Paper. 1 - 10. 
Carpenter, V. and Feroz, E. 1992. GAAP as a symbol of legitimacy: New York State's decision to adopt generally accepted accounting principles. Accounting Organizations and Society. 1 - 17

Chakrabarty B. 2007, Is it Meaningful to Measure Performance in Government Sector?. Vidyasagar University Journal of Commerce (Vol. 12), 1 - 22.

Djunaedi A. 2000 Perencanaan Strategis : Kajian dari Perspektif Perencanaan Publik. Pedoman Penyusunan Anggaran Berbasis Kinerja, 1 - 25.

Dobell, Peter dan Ulrich M. 2002. Parliament's performance in the budget process: A case study. Policy Matters. $1-27$.

Eccles, R. G. and Pyburn, P. J. 1992. Creating a comprehensive system to measure performance. Management Accounting, 1 - 17.

Fozzard A. 2001. The Basic Budgeting Problem Approaches to Resource Allocation in the Public Sector and their Implications for Pro-Poor Budgeting. Working Paper. 1 - 32.

GFOA. 2007. Performance measurement: Using performance measurement for decision making, Issues in Public Sector Performance Measurement, 1 - 40.

Gomes S P. Mendes M. S. Carvalho B. J. 2007. Performance Measurement of the Portuguese Police Force using the Balanced Scorecard. 4th International Conference on Accounting, Auditing and Management in Public Sector Reforms, 11th Biennial CIGAR Conference, $1-28$.

Guthrie, J. English, L. 1997, Performance information and program evaluation in the Australian public sector", International Journal of Public Sector Management, (Vol. 1), $1-22$.

Hagen J. von. 2005, Political Economy of Fiscal Institutions, Discussion Paper, 1 17.

Hoque $\mathrm{Z}$ and Adams C. 2008. P ector Performance, A study of government deportments in Australia, 1 -

Jackson, P. 1993. Public Service Performance Evaluation : A Strategic Perspective. Public Money \& Management. 1 - 20.

John's, St. NL, 2004, Strategic Planning. Learner's Edition Excellence in Governance : An Orientation for Public Sector Bodies, 1 - 23.

Jones, D. S. 2000. Uses and limitations of performance measurement in the civil service: An assessment from the Singapore and New Zealand experiences. Asian Journal of Political Science, $1-28$

Kaplan, R. S. 1983. Measuring manufacturing performance: A new challenge for managerial accounting research. The Accounting Review. 1 - 15

Kaplan, R. S. and Norton, D. P. 2004. Strategy maps: Converting intangible assets into tangible outcomes. Boston: Harvard Business School. 
1996. Using the Balanced Scorecard as a Strategic Management System, Harvard Business Review.

-----. 2001. Translating Strategy Into Action, Harvard Business School Publishing Corporation.

---------. 2001. The Strategi Focused Organization, Harvard Business School Publishing Corporation.

Kaufman J.L.; Jacobs, H.M. 1996. A Public Planning Perspective on Strategic Planning, Journal of the American Planning Association, (Vol . 53, No. 1), $1-25$.

Kloot, L. and Martin, J. 2000. Strategic performance management: A balanced approach to performance management issues in local government', Management Accounting Research, (Vol. 11), 1-30.

Kompas [Jakarta], I3 Juli 2003. Darmansjah I. Gerakan Jalan Lurus dalam Masyarakat yang Menyimpang, Rubrikk Opini,.

Krina P. L. L. Dra. 2003, Indikator Alat Ukur Prinsip Akuntabilitas, Transparansi dan Partisipasi. Jurnal Badan Perencanaan Pembangunan Nasional, 1 - 26.

Lembaga Administrasi Negara, 2003, Keputusan Kepala Lembaga Administrasi Negara Nomor : 2391/IX/6/8/2003 tentang Perbaikan Pedoman Penyusunan Pelaporan Akuntabilitas Kinerja Instansi Pemerintah, 1 - 40.

Mardiasmo. 2006. Pewujudan Trans ; i dan Akuntabilitas Publik Melalui Akuntansi Sektor Publik : Suatu Sarana Good ance, Jurnal Akuntansi Pemerintah (Vol. 2. No. 1), 1 - 30.

Metawie M dan Gilman M DR. 2005, Problems With The Implementation of

Performance Measurement Systems in The Public Sector whete Performance is Linked to Pay : a Literature Review Drawn form The UK, 3rd Conference on Performance Measurements and Management Control, 1 - 23.

Moleong.J. L. 1989. Metodologi Penelitian Kualitatif, Bandung: Remadja Karya.

Murwanto R., Budiarso A., Ramadhana F. H., 2007, Audit Sektor Publik, Suatu Pengantar Bagi Pembangunan Akuntabilitas Instansi Pemerintah, Lembaga Pengkajian Keuangan Publik dan Pelatihan Keuangan Departemen Keuangan RI.

Nasution S. 1988, Metodologi Penelitian Naturalistik Kualitatif. Bandung: Tarsito.

Neale A and Bruce A 2000. Performance Reporting for Accountability Purposes - Lessons, Issues, Future, International Public Management Workshop, 1 - 34.

Niven P. R 2003. Balanced Scorecard Step-by-Step for Government and Nonprofit Agencies, John Wiley \& Sons.

OPM and CIPFA. 2004. The Good Governance Standard for Public Services, Guidance of public services, The Independent Commission on Good Governance in Public Services, $1-42$. 
Pemerintah Republik Indonesia, Undang-undang Nomor 25 Tahun 2004 tentang Sistem Perencanaan Pembangunan Nasional

----------------, Undang-undang Nomor 22 Tahun 2009 tentang Lalu Lintas dan Angkutan Jalan

----------------, Peraturan Pemerintah Nomor 58 Tahun 2005 tentang Pengelolaan Keuangan Daerah

Power, M. 1997. The audit society - Rituals of verification. Oxford University Press. Presiden Republik Indonesia, 1999, Instruksi Presiden Republik Indonesia Nomor 7 Tahun 1999 tentang Akuntabilitas Kinerja I Pemerintah.

Royal Statistical Society, 2003, Performance indicators: Good, bad and ugly. 1 - 10. http://www.rss.org.uk. 12 Agustus 2010

Smith J. M. 2006. Using a Balanced Scorecard as a Strategic Tool in Public Purchasing, International Public Procurement Conference Proceedings, 1 -35 .

Stanbury, W.T. 2003. Accountability to Citizens in the Westminster Model of Government: More Myth Than Reality, Fraser Institute Digital .Publication, Canada: 1 - 46

Suprasto H. B. 2006, Peluang dan Tantangan Implementasi Anggaran Berbasis Kinerja. Buletin Studi Ekonomi (Vol 11 No 3), 24 - 36.

Transportation Research Board. 2004. Strategic Planning and Decision Making in State Departments of Transportation. A Synthesis of Highway Practice. 1 - 82.

UNDP, 2000, Dokumen Kebijakan UNDP : Tata Pemerintahan Menunjang Pembangunan Manusia Berkelanjutan. buletin informasi Program Kemitraan untuk Pembaharuan Tata Pemerintahan di Indonesia, 1-16.

U.S. General Accounting Office, 1980, Performance Budgeting: Past Initiatives Offer Insights for GPRA Implementation, GAO/AIMD, 1- 46.

Willett R, 2003, Establishing and Assessing Criteria for Judgement of Effectiveness of The Balanced Scorecard in a Large Australian Local Government Authority, Working Paper, 1-42.

Wilopo, 2003, Improvisasi Manajemen Strategi Sektor Publik. Jurnal Administrasi Negara (Vol III, No.1), 1 - 23.

Yin, R. K, 1994. Case study research. Beverly Hills.

Yuwono, S., I.T. Agus, dan Hariyandi. 2005. Penganggaran Sektor Publik, Pedoman Praktis, Penyusunan, Pelaksanaan dan Pertanggungjawaban APBD (Berbasis Kinerja). Bayumedia Publising, Malang 